The International Journal of
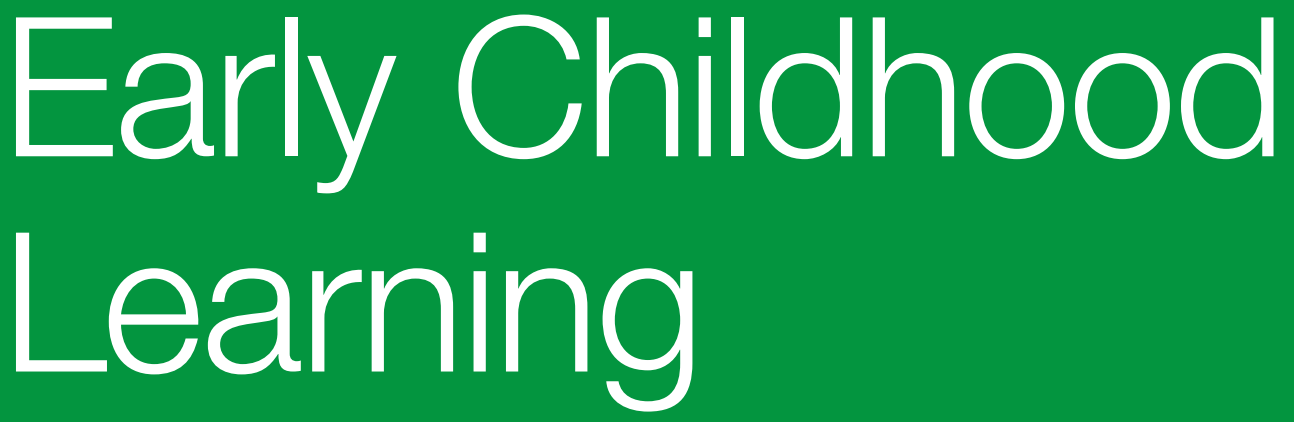

Developing Early Literacies in Informal Settings

The Importance of Cultural Representation in an Aboriginal Playgroup 


\section{EDITORS}

Bill Cope, University of Illinois, USA

Mary Kalantzis, University of Illinois, USA

\section{HEAD OF JOURNAL PRODUCTION}

McCall Macomber, Common Ground Research Networks, USA

\section{EDITORIAL ASSISTANT}

Crystal Lasky Robinson, Common Ground Research Networks, USA

\section{ADVISORY BOARD}

The Learner Research Network recognizes the contribution of many in the evolution of the Research Network. The principal role of the Advisory Board has been, and is, to drive the overall intellectual direction of the Research Network. A full list of members can be found at http://thelearner.com/about/advisory-board.

\section{PEER REVIEW}

Articles published in The International Journal of Early Childhood Learning are peer reviewed using a two-way anonymous peer review model. Reviewers are active participants of The Learner Research Network or a thematically related Research Network. The publisher, editors, reviewers, and authors all agree upon the following standards of expected ethical behavior, which are based on the Committee on Publication Ethics (COPE) Codes of Conduct and Best Practice Guidelines. More information can be found at:

http://thelearner.com/journals/model.

\section{EARLY CHILDHOOD LEARNING}

http://thelearner.com

ISSN: $2327-7939$ (Print)

ISSN: 2327-8722 (Online)

http://doi.org/10.18848/2327-7939/CGP (Journal)

First published by Common Ground Research Networks in 2018

University of Illinois Research Park

2001 South First Street, Suite 202

Champaign, IL 61820 USA

$\mathrm{Ph}:+1-217-328-0405$

http://cgnetworks.org

The International Journal of Early Childhood Learning

is a peer-reviewed, scholarly journal.

\section{COPYRIGHT}

(C) 2018 (individual papers), the author(s)

(C) 2018 (selection and editorial matter)

Common Ground Research Networks

\section{(ㅇ)(1) $(5)$}

Some Rights Reserved.

Public Licensed Material: Available under the terms and conditions of the Creative Commons Attribution-NonCommercial-NoDerivatives 4.0 International Public License (CC BY-NC-ND 4.0). The use of this material is permitted for non-commercial use provided the creator(s) and publisher receive attribution. No derivatives of this version are permitted. Official terms of this public license apply as indicated here: https://creativecommons.org/licenses/by-nc-nd/4.0/legalcode

\section{Crossref}

\section{ARTICLE SUBMISSION}

The International Journal of Early Childhood Learning publishes biannually (June, December). To find out more about the submission process, please visit http://helearner.com/journals/call-for-papers.

\section{ABSTRACTING AND INDEXING}

For a full list of databases in which this journal is indexed, please visit http://thelearner.com/journals/collection.

\section{RESEARCH NETWORK MEMBERSHIP}

Authors in The International Journal of Early Childhood Learning are members of The Learner Research Network or a thematically related Research Network. Members receive access to journal content. To find out more, visit http://thelearner.com/about/become-a-member.

\section{SUBSCRIPTIONS}

The International Journal of Early Childhood Learning is available in electronic and print formats. Subscribe to gain access to content from the current year and the entire backlist. Contact us at support@cgnetworks.org.

\section{ORDERING}

Single articles and issues are available from the journal bookstore at http://cgscholar.com/bookstore.

\section{HYBRID OPEN ACCESS}

The International Journal of Early Childhood Learning is Hybrid Open Access, meaning authors can choose to make their articles open access. This allows their work to reach an even wider audience, broadening the dissemination of their research. To find out more, please visit http://thelearner.com/journals/hybrid-open-access.

\section{DISCLAIMER}

The authors, editors, and publisher will not accept any legal responsibility for any errors or omissions that may have been made in this publication. The publisher makes no warranty, express or implied, with respect to the material contained herein. 


\title{
Developing Early Literacies in Informal Settings: The Importance of Cultural Representation in an Aboriginal Playgroup
}

\author{
Criss Jones Diaz, University of Western Sydney, Australia \\ Liam Morgan, ${ }^{1}$ University of Technology, Sydney Australia \\ Andrew Chodkiewicz, University of Technology, Sydney Australia
}

\begin{abstract}
This paper presents the results of a yearlong study within an Aboriginal playgroup on the outskirts of Western Sydney. Using a methodology that was collaborative and iterative and gathering data through a participant ethnographer who was herself Aboriginal, enabled a clear view of the impact of literacy strategies that were implemented in consultation with mothers and the playgroup leader. It was found that Aboriginal texts, stories, songs, and dance, arranging for children to experience various Aboriginal cultural events, as well as talking about and modeling language interactions, led to increased and regular child and child-adult literacy interactions. Longer-term impacts relating to home literacy practices and transition to school were also reported.
\end{abstract}

\section{Keywords: Australian Aboriginal, Safe Spaces, Strengthening Literacies,} Disadvantage, Cultural, Linguistic and Social Capital

\section{Introduction}

$\mathrm{E}$ ngaging and involving Indigenous children and their families in early childhood programs remains a significant challenge. Despite continuing policy changes and reviews and a focus on formal preschool programs, the need remains for informal, culturally strong, Indigenous early childhood programs in safe Aboriginal and Torres Strait Islander (ATSI) run spaces. Programs where the culturally based beliefs, values, and practices of the families and communities using the service are valued and included and where efforts are made to reconnect children and families with their Aboriginal culture(s) have been recognised as having a key role in improving the social and emotional wellbeing of Aboriginal children (Guilfoyle et al. 2010; Larkins 2010). The term "safe spaces" refers to spaces where participants feel confident in participating in and collaborating with those practices that actually constitute the space. They are spaces where participants feel that they can express themselves through their own linguistic and cultural practices knowing that those around them share common language, culture and life experiences.

Aboriginal and TSI families continue to face systemic and structural disadvantages in relation to income, employment, education, and housing (SNAICC 2011). This operates within a context of marginalization, disadvantage, and disconnection from traditional cultures and languages. This article examines selected data from a larger study (Morgan, Chodkiewicz, and Pennycook 2014), focusing on one Aboriginal supported playgroup in outer western Sydney. It outlines a number of strategies for working in a safe Aboriginal family space including having a focused, but nuanced, approach to supporting early literacies and acknowledging connections to country, language, and culture. The data presented in this article highlights three themes that demonstrate the significance of safe spaces for literacy learning and the importance of representation and connections to Indigenous cultural and linguistic practices. Theme 1 demonstrates ways in which the playgroup's facilitation of a safe space engendered confidence in

\footnotetext{
${ }^{1}$ Corresponding Author: Liam Morgan, 235 Jones St., School of Education, University of Technology, Sydney, New South Wales, 2007, Australia. email: Liam.Morgan@uts.edu.au
} 
practices of the participating families is also considered under this theme. Theme 3 emphasises the importance of engaging adults and children by making explicit connections to Indigenous cultural heritage and language.

\section{Marginalisation, Disadvantage, and Early Literacy Learning in ATSI Communities}

In New South Wales (NSW) the most disadvantaged Indigenous communities live in remote and regional centres (Abbott et al. 2015), although urban communities also face significant persistent disadvantage. Among the urban Aboriginal communities, most Aboriginal children in Sydney now live in outer western and south-western suburbs of Sydney (Commission for Children and Young People 2013). Aboriginal children in the Sydney region still live in the most socioeconomically disadvantaged parts of outer Sydney. For the most part, these children's families have relatively low incomes, live in mostly social or public housing, and experience higher than average levels of unemployment and lower levels of school completion (ABS 2017)

Children from ATSI families also encounter disadvantage across all levels of education including early childhood (Audit Office of NSW 2012; FaHCSIA 2012a; Nepal and Brown 2008). Despite a range of recent Australian and state government efforts and initiatives aimed at "Closing the Gap" between Indigenous and non-Indigenous communities (Australian Government 2013), Indigenous children's lower levels of participation in early childhood programs continues. These participation figures relate to both formal programs such as preschool and long day care and to informal settings such as supported playgroups (SCRGS 2013; FaHCSIA 2012a). The benefits of participation in prior to school activities such as supported playgroups are well recognised and particularly important for disadvantaged families (Hewitt and Walter 2014). These benefits can play out throughout a child's first year at school and include enhanced literacy, numeracy, cognitive, and problem-solving skills (Harrison et al. 2010).

\section{Safe Spaces, Aboriginal Services, and Cultural Representation}

The metaphor of a "safe space" when applied in educational settings encapsulates what is necessary for successful learning and engagement. The term was used by Martin (Conteh, Martin, and Robertson, in Conteh and Brock 2011, 349). Martin builds on Bhabha's notion of the "third space" in relation to African Caribbean supplementary schools; it describes the relationship between the construction of culture, identity, and space as fluid, changing and agentive in which diverse communities are able to create for themselves opportunities for meaning-making and identity construction through language and cultural representations (Conteh and Brock 2011).

Meaningful or "safe" learning spaces are sites in which children and their families are at the centre. They are spaces that encourage co-construction and collaboration of the nature of the space itself (Conteh and Brock 2011; Robinson and Jones Diaz 2016). Such spaces are actively constituted through the language, the practices, and the artefacts that directly relate to the participants sense of their own identity. Aligning with this perspective is the acknowledgement that the key strategies that facilitate Indigenous safe spaces, include establishing Indigenous early childhood services (Guilfoyle et al. 2010), the employment of trained Indigenous staff (Whyte 2012), the inclusion of Aboriginal and TSI cultural representations, and the facilitation of connections to local communities. It has been shown in a number of studies that employing Aboriginal staff in early childhood programs significantly increases Aboriginal children's attendance and family involvement (Whyte 2012; Mann, Knight, and Thomson 2011). In addition, Fluckiger and Diamond (2012) have also argued that genuine collaboration and leadership can occur in such spaces where leadership, power, and responsibilities are shared. Such collaboration requires long-term building of strong cultural identity, the establishment of trust between staff and community members, and operating in locations and under conditions 
considered culturally appropriate and "safe" by the local Indigenous community (Colquhuon and Dockery 2012).

\section{Strengthening Literacies through Connecting with Indigenous Languages and Cultures}

Through the establishment of safe spaces, the collaborative implementation of strategies designed to privilege Indigenous knowledge, texts, and other resources enable playgroup staff, parents and carers "to transform texts and contexts to support students in drawing on those resources" (Long et al. 2013, 423-24). In practice this means connecting with Indigenous cultures (Larkins 2010; Guilfoyle et al. 2010); engaging with Indigenous stories, books, and cultural events (Hill, Colbung, and Glover 2011); teaching Aboriginal and TSI languages (Williams 2011); and home literacy and parent support programs such as home visiting, shared book reading programs, and integrated services (Sims 2011).

The provision of age appropriate Aboriginal stories and books and participation in Aboriginal cultural events facilitates engagement and reconnection to aspects of Indigenous cultures (Hill, Colbung, and Glover 2011). Importantly, Aboriginal and TSI families living in major urban settings are often more disconnected from their cultural practices, languages, and affiliations than families in remote or regional settings (FaHCSIA 2012a). For example, the Longitudinal Study of Indigenous Children, (LSIC) Footprints in Time data from the Western Sydney cohort of four and five year olds revealed that "parents in Western Sydney were less likely to take their children to Indigenous cultural events, ceremonies and sorry business than parents located elsewhere... [and significantly] less likely to teach their children traditional arts" (FaHCSIA 2012b, 3).

Among the key strategies relating to connection with culture include quality access to Aboriginal and TSI languages, especially in early childhood and primary school years (Williams 2011). The LSIC Footprints in Time data found that only one in five children were reported to speak an Indigenous language (Verdon and McLeod 2015). The LSIC Footprints in Time data from Western Sydney also reports that only about 12 percent of the four- and five-year-old Aboriginal children in their cohort were learning an Aboriginal language, compared to 22 percent of all the Aboriginal children across Australia (FaHCSIA 2012). Identification with culture and language has been shown to form an important element in the development of early literacy (Morgan, Chodkiewicz, and Pennycook 2014).

\section{Theorising Safe Spaces}

In recognizing and validating that Indigenous families and children bring particular cultural knowledge and dispositions to the literacy learning process (Robinson and Jones Diaz 2016), this study builds on Bourdieu's concepts of capital, habitus, and field to highlight the notion of how "safe space" can be applied to early literacy learning in playgroup settings which privilege the social, cultural, and linguistic resources of Indigenous children and their families. This study demonstrates how the provision of safe spaces can activate ATSI cultural, linguistic, and social capital to extend children's literacy learning.

According to Bourdieu and Wacquant $(1992,119)$ social capital is "the sum of the resources, actual or virtual, that accrue to an individual or a group by virtue of possessing a durable network of more or less institutionalised relationships of mutual acquaintance and recognition." Within the immediate and extended family, this may involve relationships and collaboration that enables access to resources within the broader community. These relationships build on reciprocity and cooperation in accessing educational outcomes and opportunities for their children resulting in the transfer of social capital. However, Cheong (2006) notes that social capital is but one aspect that operates within the larger social context in which minority communities (and families) operate. Therefore, acknowledging the accumulation of other forms 
of capital as conceptualized by Bourdieu is critical to the planning of effective early literacy learning in children from Indigenous backgrounds.

Cultural capital as theorized by Bourdieu (1990) refers to the forms of advantage acquired by some as part of life experience, including family, language background, knowledge, and education. It involves cultural "habits and dispositions" that when transmitted from parents to children can assist with their success at school (Lareau and Weininger 2003). For Bourdieu cultural capital includes various forms of linguistic capital, which are specifically the language resources, knowledge, and other representational resources that are inculcated over time through social and cultural practices that inform literacy learning. In early childhood education the early literacy practices that yield recognition and legitimacy are mostly those found in standard English-only language and literacy practices emphasising monolingualism (Jones Diaz 2014). Hence forms of cultural and linguistic capital constituted in Aboriginal English are often rendered as inferior to standard Australian English reinforcing deficit assumptions and discourses of vulnerability in the literacy learning process in the minds of many early childhood educators.

The contribution of Indigenous knowledge to children's literacy learning highlights the relevance of cultural and linguistic capital. This was evident in Hare's $(2012,2)$ study in Canadian First Nation reserve communities that found within the families there was "a literacy orientation within their indigenous knowledge systems that, draws on oral tradition, land-based experiences and ceremonial practices." This study also pointed to the relevance of cultural practices inherent in songs, dances, drumming, hunting, and preparing traditional food and knowledge of medicines and symbolic representations to children's literacy learning.

Habitus involves the incorporation of dispositions, perceptions, and attitudes often inculcated in the early years (Bourdieu 1990). These practices and dispositions often reflect the social and cultural conditions within which they are acquired and therefore can produce both individual and collective practices, thoughts, and attitudes that constitute systems of dispositions (Jones Diaz 2014). For example, strong affiliations and engagement with Aboriginal cultural practices and languages can produce a confident approach towards the literacy learning process and dispositions of pride towards their Aboriginal cultural identity. This was highlighted in Colquhoun and Dockery's (2012) study, which highlighted the strengths in Aboriginal families' maintenance of strong connections to Aboriginal cultural practices resulting in children's positive social and emotional wellbeing. The children's knowledge of their Aboriginal culture was considered important by their parents, which involved "knowing about their cultural heritage, country, being proud of their Indigenous culture, knowing their language, and having connections to the family and the community, strong identity, learning the stories about the elders, sense of belonging and pride" (8).

Playgroups settings are places where families and children come together to share and connect with social and cultural practices. When these practices are validated and integrated into literacy learning experiences, the knowledge, skills, and resources constituted in these practices are converted into other forms of capital such as linguistic capital, which facilitates literacy learning (Robinson and Jones Diaz 2016).

\section{Methodology}

In the light of the above, the main aim for this research was to investigate ways of strengthening and building upon early literacy practices in an Aboriginal playgroup in ways that were culturally and linguistically appropriate, collaborative, and participatory. The key questions that guided this research were: 
1. How can families in relatively disadvantaged communities best be engaged and supported in developing their children's early literacy practices in ways that recognise their cultural and linguistic background?

2. What are the best approaches for engaging disadvantaged or vulnerable families in informal settings that are culturally and linguistically appropriate?

The methodological framework adopted for this study was one of participatory ethnography (Carspecken 1996). This process meant that, before any data were collected, extended discussions were held with playgroup staff regarding the aims and extent of the project. Their participation in the planning processes, in the selection of the participant researcher, and in the selection of the observational tools to be used was an important part of this process. The ethical considerations of working with vulnerable Aboriginal mothers were carefully considered and no initiatives were undertaken without full consultation with the playgroup leader and the mothers and carers in the group. The strategies around the introduction of books, resources, and activities were all planned following consultations and continuously evaluated in close collaboration between the researcher, playgroup staff, and the mothers and carers. This foundation was important from an ethical standpoint, and it also contributed to the richness of the data gathered.

These data, in the form of observational and field notes from the interviews with mothers, were collected over the school year with the assistance of a female Dharug Aboriginal researcher, acting as participant observer, who, following induction, attended each week for the full ninety minutes of the playgroup. In addition, an academic with expertise in the development of early literacy also visited and took part in many activities. She was able to lend her expertise to the gathering of data and the collaborative construction of a number of literacy activities.

During the first term, the focus of the Aboriginal researcher was on getting to know mothers, children and staff. She took part in playgroup and assisted staff and mothers in a variety of ways apart from the normal playgroup routines. As an older Aboriginal woman, with her deep knowledge of local Dharug country, she was accepted and respected by the mothers and carers in the group. Her quiet engagement with mothers in the group gave them the confidence to bestow the trust on her that was necessary for data collection that followed in Term 2. Participation was continued during this phase, but the researcher would also make notes and quietly interview mothers and staff as opportunities arose. Interviews with the Aboriginal researcher toward the end of the program also formed an important part of the data gathered over the course of the study.

Over the year, the number of families and children attending the playgroup varied considerably. During Term 1 the number of children attending the playgroup ranged from a high of ten children on a day to a low of six children a day. During Term 2 illness had an impact and attendance at the two-hour sessions ranged from nine children down to a low of one and three. However attendance improved during Terms 3 and 4. The numbers attending in Term 3 ranged from up to seventeen children a day to a low of eight. While in Term 4 there were a maximum of sixteen children attending each session down to a low of nine children attending on a day.

As the relationship between the researcher and the mothers and workers developed, a limited amount of video and audio data was also collected during Term 4. A number of pro-formas were used to track aspects of engagement of individual children over the course of the study and informal conversations with six of the mothers and the playgroup coordinator were also written up and used to gather information on practices around family literacies such as storytelling. The process was iterative, so that checks with the mothers and playgroup coordinator helped to shape the interviews and the focus of the observations. Recordings were also made of interactions between the researcher and five children around joint activities such as reading or play. The children were chosen randomly for these recordings. The research design drew on the work of Carspecken (1996) and that of Blommaert (2010). Carspecken's emphasis on reconstructive analysis and dialogical data generation was important and provided a means of checking 
judgments with the playgroup participants and the participant observer herself. The data were analysed using NVivo and a number of levels of thematic analysis were undertaken. However, prior to this analysis, meetings were held among the research team in order to identify key themes emerging from the raw data and check understanding with the participant observers and literacy consultant.

An important focus of the observations was the development of "language events." This concept was drawn from the concept of "literacy events" as explained by Street (2001). Language events are situations where "things are happening and you can see them happening..." (Street 2001, 10). They signal a potential for a pattern of similar events that could then be referred to as language practices. The notion of language events allows for the conceptualization of oral language, and modes such as gesture, gaze, and proximity as components of patterns that can form important building blocks of emergent literacy. It also highlights the role of the parent or adult interlocutor in scaffolding the child's language and learning (Hammond and Gibbons 2001).

\section{Context of the Research}

The playgroup was located in an outer western Sydney suburb and ran once a week for two hours during school terms, over forty weeks in the year and was provided at no cost to the families. The group was led by Aboriginal staff at an Aboriginal child and family centre, located in the middle of a government housing estate on the western urban fringe of Sydney, almost fifty kilometres from the centre of the city. As the local area had limited public transport, the provision of a small mini-bus enabled the families and children access to the centre's activities and the playgroup.

\section{Findings and Discussion}

The section that follows is structured around the three key themes that emerged from the data analysis. The first of these themes relates to the playgroup's successful facilitation of a safe space for Indigenous children and their families through a strong mission around Aboriginality and self-determination. This engendered confidence among children and adults to engage in various activities on their terms. The second theme relates to the impacts of a progressive focus on oral and emergent literacy learning across a range of structured and unstructured learning experiences. The third theme that emerged from the analysis relates to the impact of representations of Indigenous cultural and linguistic practices that were designed to make explicit connections to Indigenous cultural heritage and language and engage the adults and children in the program in a meaningful way.

\section{Theme 1: Safe Social Space for Indigenous Children and Their Families}

The notion of "safe spaces" was evident at the case study site as it provided a physically and emotionally safe Aboriginal space for women and children to come together. For the children the playgroup afforded them opportunities for a variety of learning experiences, while the mothers were able to socialise, make connections to each other, receive support from the workers, and access other services. In this context, the program was effectively integrated and negotiated around an agenda of supporting the women with issues of disadvantage, racism, poverty, domestic violence, drugs and alcoholism, mental health, violence, and gender inequality. The centre was recognised in the wider local community as an Aboriginal women's community space-providing a range of culturally appropriate services, specifically for families and children. To this end, it was a safe Aboriginal women's space, in a relatively disadvantaged and under-resourced area as evidenced in the extract below according to the Aboriginal researcher's observations. 
The whole playgroup - mums and children - is very, very relaxed, very easygoing. The mums and the children are quite comfortable there, with each other, with the workers. Everything just seems to flow. There's no pressure on anybody. The mums I think feel safe there. It doesn't matter what they're doing, how they're dressed, what they're saying - they're accepted for who they are without anyone even considering where you come from because a lot of the girls have experienced similar things; they've had some amazing traumas in their lives-domestic violence, illness, drugs.

(Interview with researcher, Term 4)

The interview with the mothers attending the program highlighted that they valued the centre as an Aboriginal-run facility, led by an Aboriginal family worker, attended by a number of other Aboriginal family and community workers. For the researchers it was evident that an important way of valuing this space was to carefully negotiate access to seek involvement and collaboration around any strategies or interventions. Having an experienced female Aboriginal researcher, as the participant observer and an experienced female early childhood academic also visiting the centre over the period of the study were key factors in respecting this space.

\section{Theme 2: A Progressive Focus on Oral and Emergent Literacy Learning}

A focal point for the observational data collected in this study was children's use of language. Observations of free play and group time playgroup activities demonstrated how children's participation in the playgroup activities provided structured and unstructured opportunities for a range of interactions with a number of interlocutors in addition to their mothers and siblings. For example, during indoor and outdoor free play, craft activities in the different learning centres such as home corner and book corner, the children were observed taking part in various types of play including solitary, parallel, collaborative, and co-constructed play. They were also observed in self talk and talk with adults and children in various activities. Group times provided opportunities for children to listen to and interact with a range of texts and stories, songs, rhymes, dance, and take part in various group games. Moreover, children's engagement with these activities contributed to their learning of early and emergent literacies throughout the year, particularly when these experiences developed oral language, storytelling, and print conventions.

An analysis of language events showed that children's oral literacies at the playgroup developed and were extended over the year. It was evident that over time children were including language related to the stories and texts they experienced. In particular in their language use they were identifying and naming bush animals, numbers and counting, and identifying colours. Children were also happy to take part in a regular sit down mealtime and in various cooking activities organised by the playgroup leader. As a result children were observed expressing some of the procedural language of cooking. In the evidentiary extract below, Wendy (the playgroup coordinator) was making chocolate crackles with H (aged four), DJ (aged two), and B (aged three). 
Wendy: Let's make crackles. How many cups of rice bubbles do we need?...Let's count.

H: $\quad$ One, two, three.

Wendy: Next, coconut. How much do we need? (To H) You hold the cup; now pour it into the bowl, now the icing sugar. How many cups?... One cup.

DJ: $\quad$ I can mix it.

Wendy: Cocoa, how much: Three spoons; let's count together.

H, DJ, and B: (In unison count) One, two, three.

Wendy: Is that stirred enough? Now the patty pans. What colour is this?

B: $\quad$ Blue

H: $\quad$ Yellow

DJ: $\quad$ Red

Wendy: Now we put the mix in. Who likes cooking?

$\mathrm{H}$, DJ, and B: Me!

(Researcher field notes [verbatim] Term 2)

In this extract, the boys are keen to participate in this activity of making chocolate crackles and respond to Wendy's procedural questions using numbers to describe quantity and colours to identify the patty pans. The children also demonstrate conceptual understandings of colour and measurement by following Wendy's cooking instructions of counting and measuring quantities, adding, mixing, and identifying ingredients.

Children's books provided each week in the play area and during each session enabled the children and/or mothers to engage in collaborative reading of age appropriate texts including Aboriginal children's storybooks. While having a story time was part of the weekly program, it did not always feature as a regular activity during the first part of the year. The playgroup leader explained that the mothers and families were facing a set of complex family and community issues, and for this reason, the group did not run with a structured program and the group operated at that time more as social support for the mothers. Therefore, as observed by the Aboriginal researcher the focus was on having the mothers feel welcomed and safe:

There's no pressure on anybody. The mums I think feel safe there...Because they know that they're in a safe environment with somebody who may have had similar experiences. They can talk about how they feel about it. They are not highly vocal; they will just sit and talk to each other or stand and chat to each other quietly. But they will talk about how they felt about something that may have happened.

(Interview with researcher, Term 4)

The story time was not a structured and regular activity. Nevertheless, book reading, stories, singing, and dancing did take place informally throughout this period. However, as the year progressed, the children and mothers' involvement with books, stories, and songs became a more regular feature of the playgroup. This was guided by ongoing, collaborative consultations between the playgroup staff, the Aboriginal researcher, and the literacy consultant. Providing a focus on engaging with and supporting literacies was important in this study, as it facilitated increased involvement of both children and mothers with stories, texts, songs, and language, and importantly, with Aboriginal texts and stories. While initially the children's involvement with texts were limited, over time, the impacts of the inclusion and provision of Aboriginal texts (including nursery rhymes and CDs) became noticeable. The data showed an increase in children's and mothers engagement with texts, stories, and songs the provision of appropriate texts and resources was further enhanced through the introduction of a regular story time, featuring Aboriginal texts and talk and modelling interactions with children around literacies. This aspect of the program will be taken up in detail in Theme 3 . 
By Terms 3 and 4 having a story time and the singing of nursery rhymes were a regular feature of the program. Furthermore, informal conversations about the value of early literacy activities and modelling examples of interactive book reading with children were undertaken throughout the year by both the early childhood academic and supported throughout the year by the researcher. The data highlighted how these efforts also had a positive impact over time, both within the playgroup and at home. Mothers were observed taking up more opportunities to interact around literacies with their children and at the end of the year reported increased literacy activities at home involving their children.

During the second half of the year mothers more readily engaged with books and interacted with their children. Flexibility around the literacy activities was important, and all attempts were made to maintain the safe and informal atmosphere that was a part of this playgroup. This lead, for example, to the strategy of including books during morning tea, where books would be read to the children as they were eating. During this routine event, the children were also involved in one-on-one reading with mothers, workers, and the researchers as evidenced in the observation from the Aboriginal researcher below:

...the mothers usually sit with the children while they're having morning tea...talking to each other...usually everybody focuses on the books.

(Interview with researcher, Term 4)

This was in sharp contrast to observations of the playgroup activities in the first part of the year. From the middle of the year onwards, children were independently selecting books for collaborative reading with peers and adults. Children increasingly took the initiative in bringing books to their mothers, other mothers, our researcher, and the visiting early childhood academic. Significantly, younger children from one to four years were highly interested in the books, stories, and songs and actively participated in interactions with adults in reading and listening to stories and singing. The excerpt below from the researcher's field notes highlights the engagement of the younger children a reading activity.

Criss read an animal book with $\mathrm{H}$ and I several times. Both boys loved this book because they were able to predict the sound made by each animal, i.e., duck, monkey, parrot, donkey and snake.

After one reading from Criss, each boy took turns to turn the pages and waited for Criss to read, "... and what does the Duck say?" "Quack quack." This would go on for several reading of the book. Both boys were later observed reading collaboratively in the "playpen" sitting on the floor.

(Researcher field notes, Term 4)

\section{Increased Involvement in Literacy Practices}

Having a regular experience of storytelling, book readings, and access to culturally and age appropriate children's books at the playgroup, together with having books and a nursery rhyme CD for families to take home, facilitated children's increased involvement with language, awareness of print conventions, structure, and genres of storytelling. This also promoted children's home literacies. A number of mothers, when asked at the end of the year, indicated that there had been positive changes in their children's home literacy practices, as well as in engagement with the playgroup. Mothers reported that their children were more involved with literacy activities at home and at the group. Some children showed a keen interest in books, listening to stories, and listening and singing along to the nursery rhyme $\mathrm{CD}$ at home. Moreover, the interview data shows that a few mothers mentioned their own increased involvement at home around literacy activities with their children. They were responding more at home to their 
children's interest in books, stories, and songs. For example, one mother reported that her boys "liked being read to" at home, and they were interested in books and would sit and "go through books themselves" (field notes, Term 3). Another mother, V, commented that she did have a regular story time with her two-year-old daughter at home, and generally she organised this just before they had lunch, at a similar time to the playgroup storybook reading time (field notes, Term 1). The excerpts below are taken from the researcher's field notes and parent interviews around the take up of books and CDs at home and are representative of the engagement reported by most of the mothers:

Jessica said that her boys really liked their books and were reading them each day. $\mathrm{H}$ and B liked to read their books themselves; the younger boys liked their father to read to them, and Jessica's school-aged child liked to read the books to his younger brothers.

(Researcher field notes, Term 4)

$\mathrm{J}$ : Every afternoon, usually when my daughter comes home, they put on a nursery rhyme $\mathrm{CD}$, one of the ones I think you gave us. They sing and dance and make a hell of a noise.

Researcher: They're singing, they're doing the actions and dancing and really...

J: Yeah. B's just starting to do the actions and starting to get to know the songs. D just stands there dancing around.

Researcher: That's great. What other things do the boys like doing?

$\mathrm{J}$ : Reading. The boys like being read to. Just general outdoor play.

(Parent interview, Term 1)

\section{Theme 3: Cultural and Linguistic Representations of Aboriginality Engaged the Adults and Children in the Program}

There were a number of important aspects of Aboriginal cultural representations that also contributed to the engagement with and involvement in the playgroup. As indicated above, these included the provision of age appropriate Aboriginal children's books and Aboriginal cultural events. It is appropriate here to consider what was learnt about the nature of the disconnection of the families from their Aboriginal cultures and language and the potential for activating their latent interest and potential for the benefit of their children.

From the interviews with the mothers at the beginning of the year, when asked about their knowledge and connection to their Aboriginal culture(s) and knowledge of Aboriginal language, most of the mothers indicated their disconnection from their own Aboriginal heritage, culture, and language. Nevertheless, the mothers strongly identified as Aboriginal and were generally aware of their country and their mob, with most of the women reporting that they knew little of their own Aboriginal heritage and languages. Some mentioned they were from Taree or North Queensland, but, significantly, none were connected to the local Dharug people. Only one mother said that while she didn't know where her mob were from, that her husband was Dharug from Katoomba, and that he did know some Dharug words, played the didgeridoo, and spoke Dharug at home to the children. As a result their boys were now learning and using some Dharug words. From conversations such as these, it seemed that for many, their own childhood experiences with Aboriginal cultural practices and use of languages were limited and fragmented but the desire to for their children to make such connections was strong. The excerpt below from an interview with one of the parents is very representative of the strong desire among the mothers to know more about their culture and language. 
Researcher: ...do you use any Aboriginal language?

J: Their father does. I don't. Their father does, and I wouldn't understand half the time what he's saying.

Researcher: Where's his mob from?

J: He's Dharug. He's from Katoomba.

Researcher: Oh right, and he speaks Dharug language?

J: Not fluently, but there's probably ten or twenty words that he knows.

Researcher: Right, and he uses that language...

$\mathrm{J}$ : He uses it with the kids.

Researcher: And the children understand and respond — do they use that language back?

J: DJ's starting to. The other boys haven't. My daughter hasn't. But DJ's starting to.

He's the only one that's really picked up on it and is starting to use it.

Researcher: That's great. It's really, really good.

$\mathrm{J}$ : It is.

(Parent interview, Term 1)

\section{Aboriginal Children's Resources}

While the centre did have a set of children's books, books are expensive to buy, and, as is the case in many community based early childhood settings, resource budgets are limited. An important addition to the literacy resources of the playgroup and as a key strategy of this project was the provision of additional Aboriginal age appropriate storybooks. Where possible, big books of a title were purchased so that they could be featured in the group time readings and smaller copies provided for mothers and children to take home.

Among the available and appropriate titles purchased were Aboriginal Dream Time stories such as "The Rainbow Serpent." The animal stories featuring animals such as emu, echidna, platypus, kangaroo, crocodile, and koalas and the counting and colours books such as, 123 , were produced by Aboriginal writers and featured Aboriginal drawings. There were also a few in desert settings such as a set of Honey Ant readers from an Alice Springs Aboriginal author and Bush Bash and a few relational stories-My Place; Nan; You and Me; Two Mates.

\section{Aboriginal Cultural and Literacy Events}

The data from interviews and observations showed that the workers, mothers, and children were very positive about a number of cultural and literacy events organised for them at the playgroup over the year. They included early in the year an Aboriginal puppet show (Yarramundi Kids) that included Aboriginal characters and songs that helped with the reinforcement of children's Aboriginal identity. Later in the year with the assistance of the research team an Aboriginal cultural event - a Koomurri performance - was staged for children and parents attending the centre.

The Term 3 Koomurri performance involved a male Wiradjiri Aboriginal cultural performer from an Aboriginal cultural group from Katoomba. Dressed traditionally with ochre markings on his face and body, he played the didgeridoo, involving the children in the music and dance, with children hopping like a kangaroo and dancing like an emu and singing in Wiradjuri. By crushing up small rocks the children made up different coloured ochre paints, and then painted themselves. Throughout this experience, the children were told stories about the nearby local Wiradjuri country and the animals that were part of that country. As the data below from the field notes show, the deep engagement of the children and mothers during these activities was striking. (CP is the cultural performer and $\mathrm{K}$ and $\mathrm{R}$ are children aged four): 
Koomurri Visit-The visit by CP from Koorimurri was fantastic; the children were fully engaged, singing, dancing, painting up, and drawing. As CP drew pictures, which the children were to paint, he told them some stories of the animals. (The paintings were not done due to lack of time, but will be kept aside for the children to do in the lead up to the reptile park visit.) The older children joined in the dancing; the younger ones sat and watched or played independently.

CP had the children help break up the ochre and wet it to paint on their skin, which they enjoyed immensely. Later in the morning $\mathrm{K}$ and $\mathrm{R}$ picked up the Diges [Didgeridoo] and blew into them. CP was great with the boys, encouraging them and singing while they blew into the Diges. He was also very hands on with all of the activities with the children, the older children sat and lay on the ground while CP drew and told stories.

(Researcher field notes, Term 3)

\section{Conclusion}

Bourdieu (1990) reminds us, that education (including informal playgroup settings) is a major social field in which cultural power and inequality are reproduced. These findings point to the effectiveness of the provision of cultural fields (in this case, an Aboriginal women's safe space) in promoting Aboriginality and equity and, to some degree in this context, challenging the reproduction of inequality. The mothers attending the playgroup were readily able to activate forms of social capital in making connections with each other in a supportive and nonthreatening environment, which in turn enabled greater forms of participation in the playgroup program.

Moreover, these findings exemplify Bourdieu's concept of the habitus as a direct reflection of the social context through which it is produced. In this study, the progressive focus on early literacy on the womens' terms through Aboriginal representations of texts and cultural and linguistic practices produced a field in which literacy learning from an Aboriginal perspective was valued and legitimised. Hence, the conditions necessary to generate social practices and the uptake of literacy engagement were evident in the children's changed positive dispositions towards literacy learning.

The collaborative and sensitive use of Aboriginal texts, cultural practices, and Indigenous representations proved to be important. The use of books, stories, songs, artefacts, guest speakers, images, traditional cultural events, and the inclusion of local Dharug connections meant the playgroup setting became pivotal in generating cultural and linguistic capital in facilitating the children's connections to their Indigenous heritage through literacy learning experiences that validated Aboriginal cultural and language practices. Since the completion of the data collection, the playgroup has continued the practices introduced during the research period. The playgroup leader reports increased attendance and more successful transitions to school.

This article reported on the findings of a study that investigated the impact of the provision of cultural and linguistic resources and practices that facilitated early literacy learning in children from Indigenous backgrounds attending an Aboriginal specific playgroup setting in outer Western Sydney (Dharug country). It argued for a focused, but nuanced, approach to early literacy learning in a context of "safe space," with specific acknowledgement of the connections to country, language practices, and cultural identity. The findings highlighted the practical significance of safe spaces that encouraged and promoted a sense of belonging and agency. This in turn facilitated their children's interest and engagement in literacy learning at the playgroup. The prime lessons to be learned relate to the provision of safe, Aboriginal-run spaces where mothers and children are free to experience a range of literacy practices on their own terms, but are supported by staff, resources, and a strong early literacy program. It is also important to acknowledge the critical importance of sensitive collaboration and the involvement of mothers and carers in all decision making around the development of programs such as these. 


\section{REFERENCES}

Abbott, Elizabeth, Liz Allen, Nicholas Biddle and Heather Crawford. 2015. The Aboriginal Population of NSW in 2015: Policy Options and Challenges. Prepared for Aboriginal Affairs, NSW Department of Education, Sydney. Sydney: NSW Aboriginal Affairs.

Audit Office of NSW. 2012. Improving the Literacy of Aboriginal Students in NSW Public Schools. Sydney: NSW Auditor-General.

Australian Bureau of Statistics (ABS). 2017. National Aboriginal and Torres Strait Islander Social Survey. Canberra, Australia: Australian Bureau of Statistics.

Australian Government. 2013. Closing the Gap: Prime Minister's Report 2013. Canberra: Australian Government.

Blommaert, Jan. 2010. A Sociolinguistics of Globalization. Cambridge: Cambridge University Press.

Bourdieu, Pierre. 1990. The Logic of Practice. Stanford, California: Stanford University Press.

Bourdieu, Pierre, and Loïc Wacquant. 1992. An Invitation to Reflexive Sociology. Chicago: University of Chicago Press.

Carspecken, Phil Francis. 1996. Critical Ethnography in Educational Research: A Theoretical and Practical Guide. New York: Routledge.

Cheong, Pauline Hope. 2006. "Communication Context, Social Cohesion and Social Capital Building among Hispanic Immigrant Families.” Community, Work and Family 9 (3): 367-87. http://doi.org/10.1080/13668800600743495.

Colquhoun, Simon, and Alfred Michael Dockery. 2012. The Link between Indigenous Culture and Wellbeing: Qualitative Evidence for Australian Aboriginal Peoples. Centre for Labour Market Research Discussion Paper. Perth: Centre for Labour Market Research, Curtin University. Accessed November 29, 2017. http://www.ncsehe.edu.au/wpcontent/uploads/2013/09/2012.01_LSIC_qualitative_CLMR1.pdf.

Commission for Children and Young People. 2013. "Chapter 2: Diversity of NSW Children" In A Picture of NSW Children. Sydney: Advocate for Children and Young People. Accessed March 29, 2017. http://picture.kids.nsw.gov.au/demographic/Diversity-ofNSW-Children.

FaHCSIA 2012a. Footprints in Time: The Longitudinal Study of Australian Children. Key Summary Report from Wave 3. Canberra: Department of Families, Housing, Community Services and Indigenous Affairs.

FaHCSIA 2012b. Footprints in Time 2012: Western Sydney. Canberra: Department of Families, Housing, Community Services and Indigenous Affairs.

Fluckiger, Bev, and Patrick Diamond. 2012. "Yarning Space: Leading Literacy Learning through Family-School Partnerships." Australasian Journal of Early Childhood: 37 (3): 53-59.

Guilfoyle, Andrew, Sherry Saggers, Margaret Sims, and Teresa Hutchins. 2010. "Culturally Strong Childcare Programs for Indigenous Children, Families and Communities." Australasian Journal of Early Childhood 35 (3): 68-76.

Hammond, Jenny, and Pauline Gibbons. 2001. "What is Scaffolding?" In Teachers' Voices 8: Explicitly Supporting Reading and Writing In The Classroom, edited by Anne Burns and Helen de Silva Joyce, 8-16. Sydney: National Centre for English Language Teaching and Research Macquarie University.

Harrison, Linda, Judy Ungerer, Grant Smith, Stephen Zubrick, Sarah Wise, Frances Press, and Manjula Waniganayake. 2010. Child Care and Early Education in Australia - The Longitudinal Study of Australian Children. FaHCSIA Social Policy Research Paper No. 40. Accessed May 18, $2018 \mathrm{http}: / /$ ssrn.com/abstract=1703234.

Hare, Jan. 2012. "They Tell a Story and There's Meaning behind That Story: Indigenous Knowledge and Young Indigenous Children's Literacy Learning." Journal of Early Childhood Literacy 12 (4): 389-414. https://doi.org/10.1177/1468798411417378. 
Hill, Susan, Michael Colbung, and Anne Glover. 2011. "My Favourite Book! Young Aboriginal Children's Book Choices." Australasian Journal of Early Childhood 36 (1): 77-84.

Jones Diaz, Criss. 2014. "Literacies in Childhood Bilingualism: Building on Cultural and Linguistic Capital in Early Childhood Education." In Diverse Literacies in the Early Years: Implications for Practice, edited by Leonie Arthur, Jean Ashton, and Bronwyn Beecher, 106-125. Sydney: ACER.

Larkins Steve. 2010. "Strengthening Culture, Strengthening Identity. Keys to Healing for Aboriginal and Torres Strait Islander Children and Young People and Securing their Social and Emotional Wellbeing." Family Relationships Quarterly 17 (September): $10-13$.

Lareau, Aneiite, and Eliot Weininger. 2003. "Cultural Capital in Educational Research: A Critical Assessment." Theory and Society 33 (5-6): 567-606.

Long, Sue, Dinah Volk, Janice Baines, and Carmen Tisdale. 2013. "We've Been Doing It Your Way Long Enough: Syncretism as a Critical Process." Journal of Early Childhood 13 (3): 418-39.

Mann, Deb, Samantha Knight, and Jo Thomson. 2011. Aboriginal Access to Preschool. Sydney: SDN Child and Family Services.

Morgan, Liam, Andrew Chodkiewicz, and Alastair Pennycook. 2014. Developing Early Literacies in Informal Settings: Linguistic and Cultural Diversity and Supported Playgroups. Sydney: University of Technology, Sydney.

Nepal, Binod, and Laurie Brown. 2008. "Estimating Lifetime Socio-economic Disadvantage in the Australian Indigenous Population and Returns to Education." Paper presented at Australian Population Association 14th Biennial Conference, Alice Springs, Australia, June 30-July 3, 2008.

Robinson, Kerry, and Criss Jones Diaz. 2016. Diversity and Difference in Childhood: Issues for Theory and Practice. London: Open University Press.

SCRGS. 2013. "Chapter 3. Early Childhood Education and Care." In Report on Government Services 2013, vol. 1, 3.2-3.91. Canberra: Steering Committee for the Review of Government Service Provision, Productivity Commission. Accessed May 21, 2017. https://www.pc.gov.au/research/ongoing/report-on-government-services/2013/2013.

Sims, Margaret. 2011. Early Childhood and Education Services for Indigenous Children Prior to Starting School. Produced for the Closing the Gap Clearinghouse. Canberra: Australian Institute of Health and Welfare and Melbourne: Australian Institute of Family Studies. Accessed May 16, 2018. https://www.aihw.gov.au/getmedia/c091cf6b-c4ca-4e36-ac6125150b0b92b9/ctgc-rs07.pdf.

SNAICC. 2011. Submission Australian Government Discussion Paper: A National Children's Commissioner. Fitzroy, VIC: Secretariat of National Aboriginal and Islander Child Care.

Street, Brian V. 2001. Literacy and Development: Ethnographic Perspectives. London: Routledge.

Whyte, Sarah. 2012. "Inclusion Gets a Tick at Preschool." Sydney Morning Herald, October 14, 2012.

Williams, Shayne T. 2011. The Importance of Teaching and Learning Aboriginal Languages and Cultures. Surry Hills, NSW: Aboriginal Affairs, Office of Communities, NSW Department of Education and Communities. 
JONES DIAZ ET AL.: SAFE SPACES FOR ABORIGINAL FAMILIES AND THEIR CHILDREN

\section{ABOUT THE AUTHORS}

Dr Criss Jones Diaz: Senior Lecturer, School of Education, University of Western Sydney, New South Wales, Australia

Dr Liam Morgan: Faculty Associate, School of Education, University of Technology, Sydney, New South Wales, Australia

Andrew Chodkiewicz: Senior Research Assistant, School of Education, University of Technology, Sydney, New South Wales, Australia 


\section{The International Journal of Early Childhood}

Learning is one of ten thematically focused journals in the collection of journals that support The Learner Research Network -its journals, book series,

conference, and online community.

The journal investigates the dynamics of learning in the first seven years of life.

As well as articles of a traditional scholarly type, this journal invites presentations of practice-including documentation of early childhood learning practices and exegeses of the effects of those practices.

The International Journal of Early Childhood Learning is a peer-reviewed, scholarly journal. 